Article

\title{
gga-miR-101-3p Plays a Key Role in Mycoplasma gallisepticum (HS Strain) Infection of Chicken
}

\author{
Jiao Chen ${ }^{1}$, Zaiwei Wang ${ }^{1}$, Dingren $\mathrm{Bi}^{2}{ }^{2}$, Yue Hou ${ }^{1}$, Yabo Zhao ${ }^{1}$, Jianjun Sun ${ }^{3, *}$ and \\ Xiuli Peng ${ }^{1,2, *}$ \\ Received: 28 October 2015; Accepted: 24 November 2015; Published: 2 December 2015 \\ Academic Editor: Y-h. Taguchi \\ 1 Key Laboratory of Agricultural Animal Genetics, Breeding and Reproduction, Ministry of Education, \\ Huazhong Agricultural University, Wuhan 430070, China; chenjiao123@webmail.hzau.edu.cn (J.C.); \\ wangzaiwei@webmail.hzau.edu.cn (Z.W.); houyue@webmail.hzau.edu.cn (Y.H.); \\ zyb@webmail.hzau.edu.cn (Y.Z.) \\ 2 China National Key Laboratory of Agricultural Microbiology, Huazhong Agricultural University, \\ Wuhan 430070, China; bidingren@mail.hzau.edu.cn \\ 3 Department of Biological Sciences and Border Biomedical Research Center, University of Texas at El Paso, \\ El Paso, TX 79968, USA \\ * Correspondence: jsun@utep.edu (J.S.); xlpengsishun@mail.hzau.edu.cn (X.P.); \\ Tel.: +915-747-8905 (J.S.); +86-27-8728-1396 (X.P.); Fax: +915-747-5808 (J.S.); +86-27-8728-0408 (X.P.)
}

\begin{abstract}
Mycoplasma gallisepticum (MG), one of the most pathogenic Mycoplasma, has caused tremendous economic loss in the poultry industry. Recently, increasing evidence has suggested that micro ribonucleic acids (miRNAs) are involved in microbial pathogenesis. However, little is known about potential roles of miRNAs in MG infection of chicken. In the present study, using miRNA Solexa sequencing we have found that gga-miR-101-3p was up-regulated in the lungs of MG-infected chicken embryos. Moreover, gga-miR-101-3p regulated expression of the host enhancer of zeste homolog 2 (EZH2) through binding to the $3^{\prime}$ un-translated region (3'-UTR) of EZH2 gene. Over-expression of gga-miR-101-3p significantly inhibited EZH2 expression and hence inhibited proliferation of chicken embryonic fibroblast (DF-1 cells) by blocking the G1-to-S phase transition. Similar results were obtained in MG-infected chicken embryos and DF-1 cells, where gga-miR-101-3p was significantly up-regulated, while EZH2 was significantly down-regulated. This study reveals that gga-miR-101-3p plays an important role in MG infection through regulation of EZH2 expression and provides a new insight into the mechanisms of MG pathogenesis.
\end{abstract}

Keywords: chicken; Mycoplasma gallisepticum (HS strain); gga-miR-101-3p; EZH2

\section{Introduction}

Mycoplasmas are cell wall-less prokaryotes that are widespread in nature either as parasites or as commensals in eukaryotic hosts. Mycoplasmosis, the diseases caused by Mycoplasmas occur in animals and humans and have multiple clinical appearances [1-7]. As one of the most important Mycoplasma species [8], MG causes for avian chronic respiratory diseases, especially in chickens and turkeys in the world [9-11], with featured inflammation in the trachea, air sacs and lungs [12]. MG is known to invade, survive and multiply inside a variety of non-phagocytic cells, such as chicken fibroblasts and HeLa cells [13-16]. MG-HS strain is a virulence strain isolated from the chicken farms in Hubei Province of China $[17,18]$. MG infection in chicken farms usually lasts for a long time and is very difficult to be eliminated completely. Infected birds become life-long carriers through horizontal and vertical transmission [19]. While there are vaccines (e.g., F-strain, ts-11-strain, and 
6/85-strainvaccines) and antibiotics (e.g., Tylosin) available for prevention and treatment of MG infection, antibiotics and vaccines have no impact on the life-long carrier status of infected poultry. The increased MG epidemic has caused great economic losses in the poultry industry worldwide [20].

MiRNAs are a class of small, non-coding, single-stranded RNAs consisting of 22-25 nucleotides. Since the discovery of the first miRNA, lin-4, in Caenorhabditis elegans two decades ago [21], over 24,000 curated miRNA entries have been identified from various species [22] For chicken, more than 859 miRNAs have been identified so far [22], and only a few of them have been studied. It is well known that miRNAs can negatively regulate gene expression at the post-transcriptional level via an RNA interference (RNAi) mechanism [23]. Partial or full complementary pairing of miRNAs with target mRNAs in the 3'-UTR causes translational repression and/or degradation of mRNAs, which result in silencing of the target gene [24-28]. Therefore, down-regulation of miRNAs usually increases expression of targeted gene(s), whereas up-regulation of miRNAs leads to suppression of target genes. MiRNAs offer a fast, energy-saving and fine-tuning mechanism for post-transcriptional control of protein production [27]. It is believed that up to $30 \%$ of human protein coding genes may be regulated by miRNAs [29].

Current studies have suggested that miRNAs play important roles in various physiological and pathological processes in the avian world [23,30]. For instance, miRNAs are involved in poultry diseases, such as avian leucosis [31,32], avian influenza [33], infection bursal disease [34], Marek's disease [35-38], and ovarian carcinoma [39].

A number of studies have indicated that miR-101 is involved in a variety of diseases [40-44]. Recently, we investigated the miRNA expression profiling in the MG-infected lungs vs. the non-infected lungs of specific-pathogen-free (SPF) chicken embryos by Solexa deep sequencing (lab unpublished data). The preliminary data showed that gga-miR-101-3P was up-regulated in the MG-infected lungs, compared with non-infected lungs, suggesting that gga-miR-101-3P may play an important role in MG infection of chicken. In the present study, we identified EZH2 as the target of gga-miR-101-3P and tested the effects of the miRNA on expression of EZH2 and cell growth in the context of MG infection.

\section{Results}

\subsection{Prediction of the Target Gene of gga-miR-101-3p}

In our previous studies, we found that gga-miR-101-3p was up-regulated in the lungs of the infected chicken embryos by miRNA solexa sequencing (lab unpublished data). Since it is well documented that miRNAs exert their function through regulating expression of their target gene(s) [45], we sought to identify the direct target of gga-miR-101-3p involved in MG-HS infection. The prediction software/servers from TargetScan [46], miRBase [22], miRecords [47], and miRDB [48] were used to search the putative protein-coding gene targets of gga-miR-101-3p. Data collection and analysis revealed that EZH2 was as a potential target gene of gga-miR-101-3p (score 98.36). The predicted target site is at 94-114, with the seed region of miR-101 at 107-113 (Figure 1A). Then, we used RNAhybrid [49] to analyze the duplex and the minimum free energy (mFE between gga-miR-101-3p and EZH2 3'-UTR. MFE of RNA duplex is about $-23.8 \mathrm{kCal} / \mathrm{mole}$, indicating it has a high stability (Figure 1B). The putative target site on the $3^{\prime}-\mathrm{UTR}$ of EZH2 is highly conserved in a wide range of species, including human, mouse, dog, monkey and platypus (Figure 1C). We used AmiGo [50] to analyze EZH2 functions in Gallus gallus. EZH2 can positively regulate mitogen-activated protein kinase (MAPK) activity and cell proliferation.

Upon recognition of pathogen associated molecular patterns (PAMPs), MAPKs are activated rapidly, leading to the production of pro-inflammatory cytokines to defend against microbial infection. However, one can imagine that MG-induced up-regulation of gga-miR-101-3p in the lung tissues of chicken embryos may repress the expression of EZH2, which, in turn, prolong the activation of MAPKs, and increase tissue damage in hosts by MG infection. It is also reported that EZH2 plays 
an important role in development and differentiation of $\mathrm{T}$ cells and $\mathrm{B}$ cells and in promoting both regulatory and effector responses [51-55]. Thus, we hypothesize that gga-miR-101-3p is involved in MG-infection through regulation of EZH2 expression.

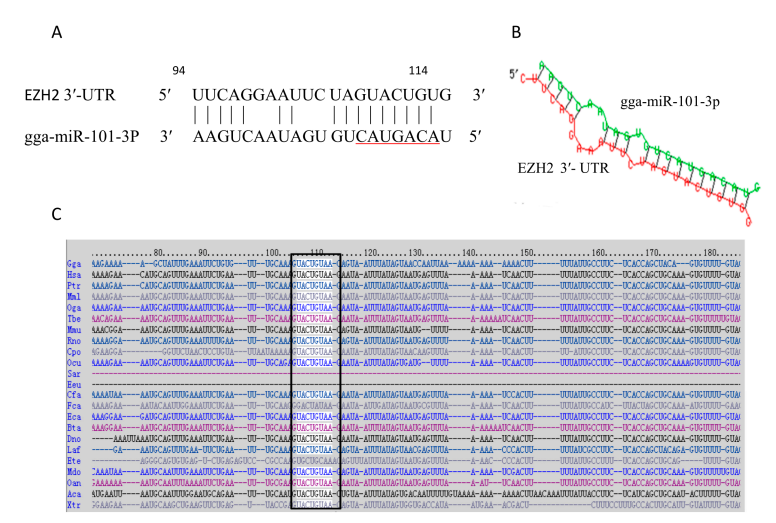

Figure 1. Prediction of the target gene of gga-miR-101-3p. (A) Sequence alignments of gga-miR-101-3p and the target site in the $3^{\prime}$-UTR of EZH2. The seed sequence of gga-miR-101-3p is underlined, and the complementary nucleotides between gga-miR-101-3p and EZH2 $3^{\prime}$-UTR are indicated; (B) Secondary structure of the RNA duplex of gga-miR-101-3p and EZH2 $3^{\prime}$-UTR target site (Red: Target sequence; Green: gga-miR101-3p); (C) Sequence alignment of EZH2 3'-UTR from different species. The conserved target sequences are highlighted. Species abbreviations refer to the website link [56].

\subsection{EZH2 Is the Direct Target of gga-miR-101-3p}

To further verify whether gga-miR-101-3p directly targets to the 3'-UTR of EZH2 in DF-1 cells, we performed a luciferase reporter assay. The target sequence of EZH2 $3^{\prime}$-UTR was cloned into a luciferase reporter vector to generate Luc-EZH2 (3'-UTR). Expression of luciferase can be inhibited by binding of gga-miR-101-3p to $3^{\prime}$-UTR of EZH2. Co-transfection of Luc-EZH2 (3'-UTR) with gga-miR-101-3p mimics (gga-miR-101-3p) in DF-1 cells resulted in a significant decrease of luciferase activity, while transfection of a non-specific RNA (miR-101-NC), did not affect luciferase activity (Figure 2). When the gga-miR-101-3p specific inhibitor (miR-101-Inh) was transfected into the DF-1 cells, the luciferase activity was significantly increased even in the presence of gga-miR-101-3p. As expected, a negative control for the gga-miR-101-3p specific inhibitor (miR-101-Inh-NC) did not inhibit EZH2 3'-UTR luciferase activity (Figure 2), which demonstrated that gga-miR-101-3p negatively regulated expression of EZH2 by binding to the complementary sequence in the $3^{\prime}$-UTR of $\mathrm{EZH} 2$ in a direct and sequence-specific manner.

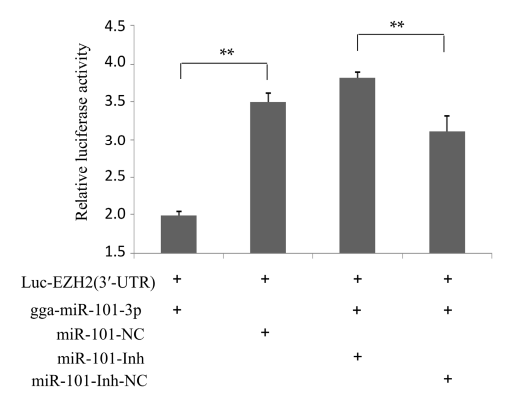

Figure 2. EZH2 is the direct target of gga-miR-101-3p. DF-1 cells were co-transfected with Luc-EZH2 ( $3^{\prime}$-UTR) and the indicated RNA oligonucleotides. At $24 \mathrm{~h}$ of post-transfection, the cells were assayed for both firefly and renilla luciferase using the dual-luciferase glow assay. Three independent experiments were performed and each sample was tested in triplicates. Data are expressed as means \pm SD. Two-tailed Student's $t$-test was used to analyze the significant differences $(* * p<0.01)$. 


\subsection{Effects of gga-miR-101-3p on EZH2 Expression}

To determine the roles of gga-miR-101-3p in regulation of EZH2 expression, we tested effects of over-expression or suppression of gga-miR-101-3p on EZH2 expression in DF-1 cells. Through transient transfection, gga-miR-101-3p was over-expressed in DF-1 cells (Figure 3A). As a negative control, miR-101-NC was over-expressed in DF-1 cells through transient transfection. In addition, a mock transfection was set as blank. Over-expression of gga-miR-101-3p, but not miR-101-NC, resulted in a significant decrease of EZH2 expression at both mRNA and protein levels (Figure 3B,C). Subsequently, over-expression of miR-101-Inh drastically inhibited gga-miR-101-3p expression (Figure 4A), which, in turn, increased EZH2 expression at both mRNA and protein levels (Figure 4B,C). The data suggest that gga-miR-101-3p negatively regulates expression of EZH2 expression in DF-1 cells through binding to the $3^{\prime}$-UTR of EZH2.
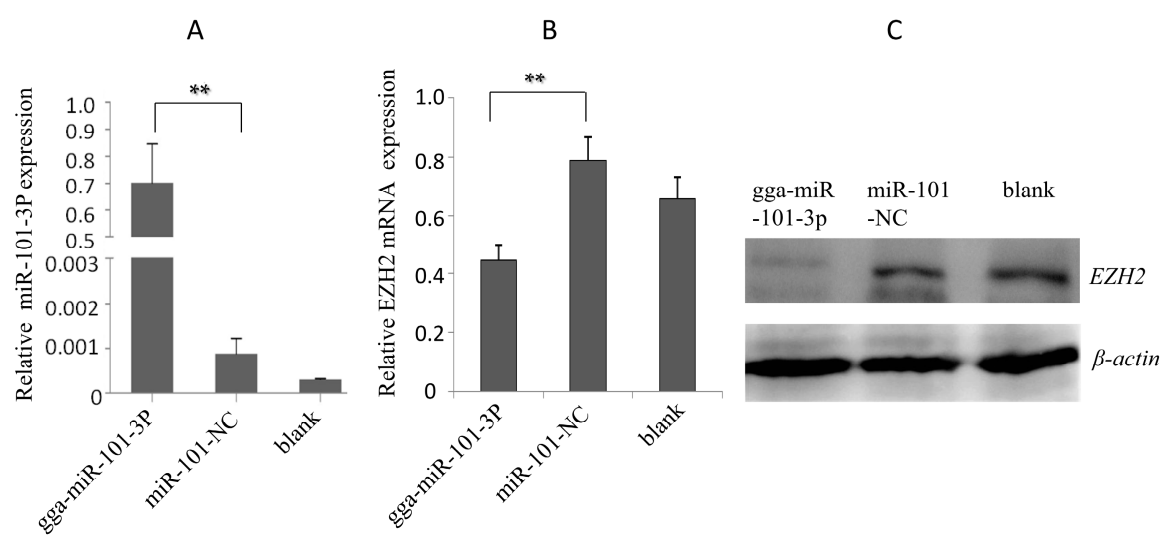

Figure 3. Over-expression of gga-miR-101-3p repressed EZH2 expression. (A) Over-expression of gga-miR-101-3p in DF-1 cells; (B) The mRNA level of EZH2 in DF-1 cells overexpressing gga-miR-101-3p was reduced. Error bars represent the mean \pm SD of triplicate experiments; (C) Western blot analysis of EZH2 protein expression in DF-1 cells transfected with gga-miR-101-3p. A mock transfection was set as a blank; the expression of $\beta$-actin was used as a loading control. Each experiment was repeated three times, and each sample was assayed in triplicate. The asterisks represented statistically significant differences $\left.{ }^{* *} p<0.01\right)$.

A

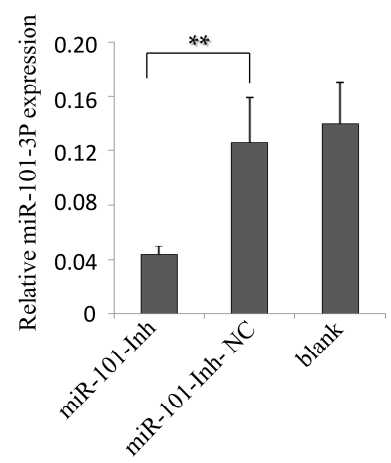

B

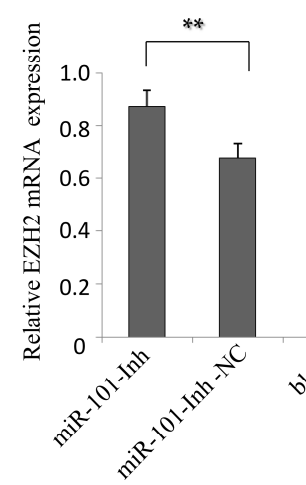

C

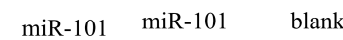

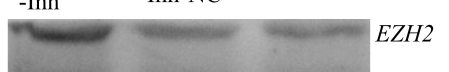

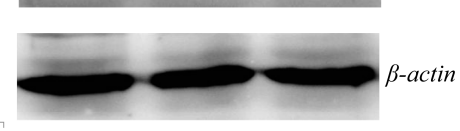

Figure 4. Inhibition of gga-miR-101-3p increased EZH2 expression. (A) Transfection of miR-101-Inh reduced the expression of gga-miR-101-3p in DF-1 cells, as detected by RT-qPCR; (B) Transfection of miR-101-Inh increased the mRNA expression of EZH2 in DF-1 cells. Error bars represent the mean \pm SD of triplicate experiments; (C) Transfection of miR-101-Inh increased protein expression of EZH2 in DF-1 cells. A mock transfection was set as a blank, and the expression of $\beta$-actin was used as a loading control. Each experiment was repeated three times, and each sample was assayed in triplicate. The asterisks represented statistically significant differences $(* * p<0.01)$. 


\subsection{Effects of gga-miR-101-3P on Cell Proliferation and Cell Cycle}

To further explore the role of gga-miR-101-3p in MG-HS infection, we examined the effects of gga-miR-101-3p on DF-1 cell proliferation. DF-1 cells were transfected with gga-miR-101-3p or miR-101-NC, and then cultured for various periods of time ( $24 \mathrm{~h}, 48 \mathrm{~h}$ and $72 \mathrm{~h})$. In addition, a mock transfection was set as a blank. Cell proliferation assay showed that over-expression of gga-miR-101-3p significantly reduced the proliferation of DF-1 cells at $48 \mathrm{~h}$ and $72 \mathrm{~h}$ of post-transfection, compared to miR-101-NC or the blank control (Figure 5).

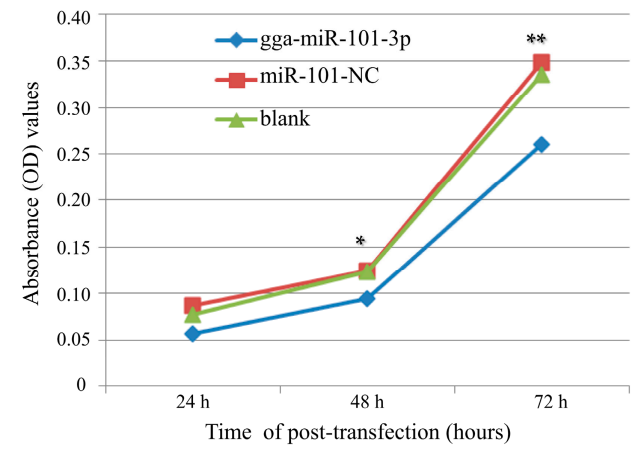

Figure 5. Over-expression of gga-miR-101-3p inhibited DF-1 cell proliferation. DF-1 cells were transfected with gga-miR-101-3p or the negative control. A mock transfection was set as a blank. At 24, 48, $72 \mathrm{~h}$ of post-transfection, the cell proliferation was measured using an MTT-Cell Proliferation and Cytotoxicity Assay Kit (Beyotime, Beijing, China). Plotted means and standard deviation were computed from data of three independent experiments, and the relative cell growth is shown. The asterisks represented statistically significant differences $\left({ }^{*} p<0.05,{ }^{* *} p<0.01\right)$.

Next, we assessed the effects of gga-miR-101-3p on cell cycle distribution by flow cytometry. In DF-1 cells, gga-miR-101-3p significantly reduced the percentage of S-phase cells, but increased the percentage of G1-phase cells (Figure 6). Taken together, these results indicate that over-expression of gga-miR-101-3p induces G1-phase arrest, which results in inhibition of cell growth and proliferation.
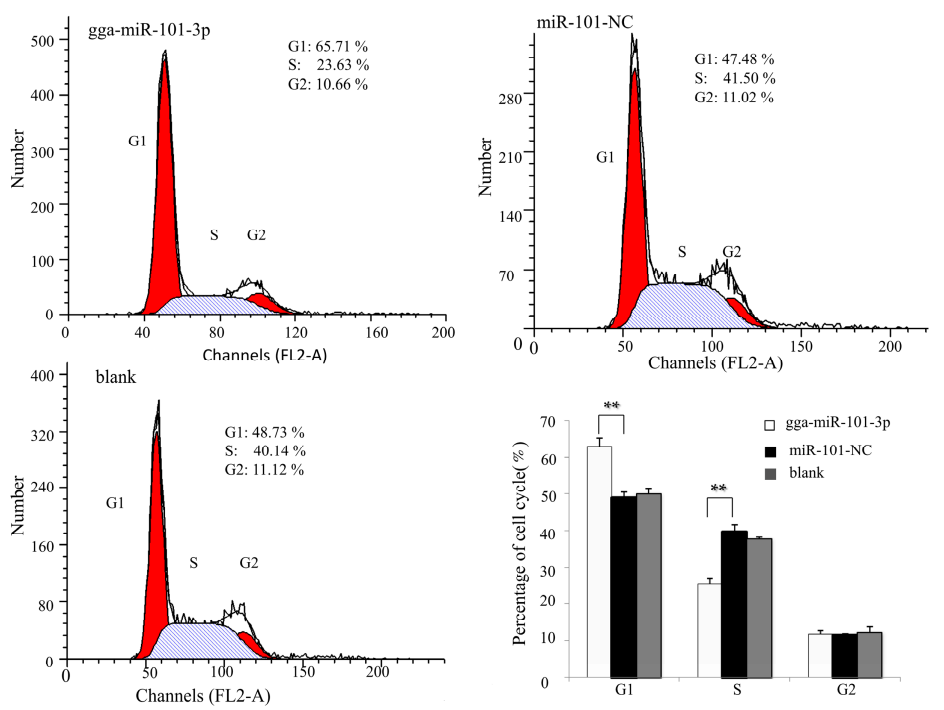

Figure 6. Over-expression of gga-miR-101-3p arrested DF1 cells at G1 phase. The DF-1 cells were transfected with gga-miR-101-3p or the negative control. A mock transfection was also performed as blank control. At $48 \mathrm{~h}$ of post-transfection, the cell phase distribution was analyzed by flow cytometry. Three independent experiments were performed in triplicate. Data are presented as means \pm SD. Two-tailed Student's $t$-test was used to analyze significant differences ( ${ }^{* *} p<0.01$ ). 


\subsection{Expression of gga-miR-101-3p and EZH2 in MG-infected DF-1 Cells and Chicken Embryos}

Upon MG infection, gga-miR-101-3p expression in DF-1 cells was significantly up-regulated (Figure 7A), while EZH2 expression was significantly down regulated (Figure 7B). The chicken embryos at the 9th day of hatching (total 21 days of egg hatching) were infected by MG-HS. On the 9th-11th days of post-infection (equivalent to the 17th-19th days of egg hatching), we observed that gga-miR-101-3p expression was significantly higher in the lungs of the MG-infected chicken embryos than the non-infected group (Figure 8A). As expected, EZH2 expression showed opposite patterns as gga-miR-101-3p on the 10th-11th days of post-infection (equivalent to the 18th and 19th days of egg hatching) (Figure 8B).

A

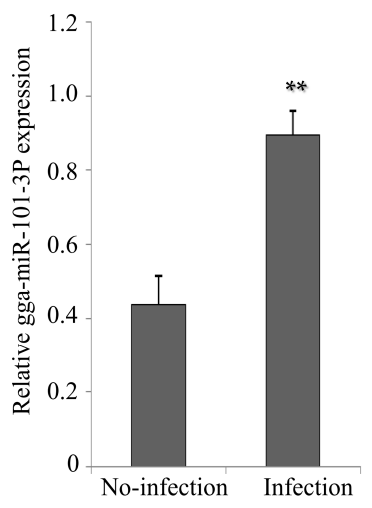

B

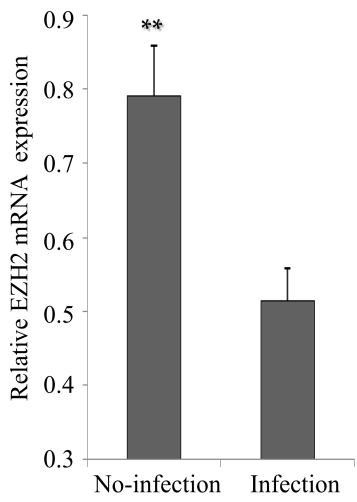

Figure 7. Effects of MG infection on the expression of gga-miR-101-3P and EZH2 in DF-1 cells. The DF-1 cells were infected by MG as described in section Material and Methods, and the total RNA was extracted. (A) gga-miR-101-3p expression was assessed by real-time quantitative reverse transcriptase polymerase chain reaction (RT-qPCR) using 5S-rRNA as an internal quantitative control; (B) EZH2 mRNA expression was assessed by RT-qPCR. GAPDH was used as an internal quantitative control. Three independent experiments were performed in triplicate, plotted data points referred to the means \pm standard deviations and asterisks represented statistically significant differences $(* *<0.01)$.

A

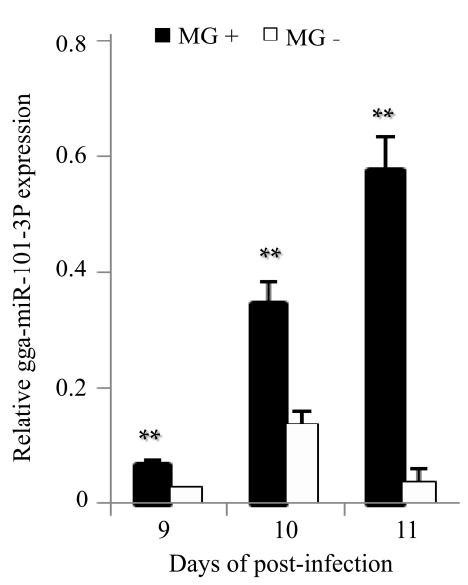

B

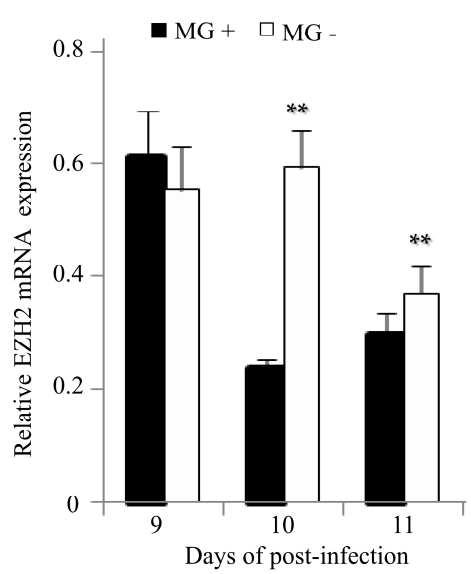

Figure 8. Effects of MG infection on the expression of gga-miR-101-3P and EZH2 in the lungs of chicken embryos. The chicken embryos were infected by MG-HS as described in section Material and Methods. On the 9th, 10th, and 11th days of post-infection, the lungs of the infected chicken embryos were processed and the expression of gga-miR-101-3p (A); and EZH2 (B) was measured by RT-qPCR. Three independent experiments were performed in triplicate, plotted data points referred to the means \pm standard deviations and asterisks represented statistically significant differences $\left({ }^{* *} p<0.01\right)$. 


\section{Discussion}

It is well documented that miRNAs can bind and silence multiple target genes, which regulate gene expression and affects malignant cellular behaviors [57,58]. Host miRNAs regulate expression of genes from pathogenic microorganism, and pathogenic microorganisms develop highly sophisticated mechanisms to evade host immune responses. In chronic respiratory diseases of chickens, some host miRNAs are aberrantly expressed. Thus, it is important to understand the roles and underlying mechanisms by which miRNAs affect Mycoplasma infection.

Our preliminary study showed that gga-miR-101-3p was up-regulated in MG-infected SPF chicken embryos (lab unpublished data). Consistent to our previous study, we found here that gga-miR-101-3p is up-regulated in MG-infected DF-1 cells and in the lung tissues of MG-infected chicken embryos. More importantly, we identified EZH2 as the target of gga-miR-101-3P. Gga-miR-101-3p negatively regulates the expression of EZH2 gene by binding to complementary sequence in the $3^{\prime}-\mathrm{UTR}$ of EZH2. Analysis by AmiGo software shows that EZH2 functions in Gallus gallus and EZH2 can positively regulate MAP kinase activity and cell proliferation [50].

Mycoplasma can induce a series of pro-inflammatory cytokines, apoptosis, or necrosis in a variety of cell types [59-61]. MAPKs are pivotal mediators of innate immune responses to microbial infection. Upon recognition of PAMPs, MAPKs are activated to produce pro-inflammatory cytokines to defend against microbial infection. In our study, gga-miR-101-3p was up-regulated in MG-infected SPF chicken embryos, which repressed the expression of EZH2. Thus, it is reasonable to believe that MG inhibits activation of MAPKs through up-regulation of gga-miR-101-3p and down-regulation of EZH2. The miRNA family of miR-101 play an important role for in regulating innate immune responses to infection. It has been reported that it inhibits a dual specific phosphatase that deactivates MAPKs [43,62], and it also regulates the MAPK response and affects the secretion of the downstream inflammatory cytokines, such as TNF- $\alpha$, IFN, IL-1, IL-6 [42].

In the present study, we found that over-expression of gga-miR-101-3p leads to cell cycle arrest. $E Z H 2$ is a growth suppressor gene and involved in the regulation of cell cycle progression and proliferation $[63,64]$.

Recent studies showed that miR-101 could target EZH2 in a variety of cancers. During prostate cancer progression, miR-101 was down-regulated, and over-expression of miR-101 suppressed proliferation of prostate cancer cells [65-67]. It is also reported that miR-101 inhibits lung cancer invasion through regulation of EZH2 [41], which inhibits cell proliferation and invasion, but enhances paclitaxel-induced apoptosis in non-small cell lung cancer [40]. Moreover, miR-101 is down-regulated in bladder transitional cell carcinoma, and directly represses EZH2 [68,69]. The miR-101 functions as a tumor suppressor in human retinoblastoma cells by targeting EZH2. It also significantly inhibits cellular proliferation, migration and invasion of gastric cancer cells by targeting EZH2 [70]. Ectopic expression of miR-101 significantly reduced cell growth and proliferation in retinoblastoma through directly targeting EZH2, which was associated with increased G1 phase arrest and cell apoptosis [71]. The miR-101 negatively regulates EZH2 in ovarian cancer cell lines, and miR-101 over-expression resulted in decreased cellular proliferation and migration [72]. Research has shown that miR-101 has been linked to tamoxifen and fulvestrant resistance by its targeting of EZH2 [73]. Both miR-101 and EZH2 are highly conserved in many different species from chicken to human (Figure 1C), suggesting that miR-101-EZH2 is a common pathway in regulating immune response in vertebrates. Thus, it is reasonable to believe that the up-regulation of gga-miR-101-3p in the MG-infected chicken inhibits EZH2 expression, which in turn suppresses proliferation and cell cycle in chicken cells.

EZH2 also plays important roles in the regulation of $\mathrm{T}$ cell activity. Recent studies found that both EZH2-deficient regulatory $\mathrm{T}$ (Treg) cellsand effector $\mathrm{T}$ (Teff) cells were functionally impaired in vivo. Treg cells failed to constrain autoimmune colitis, while Teff cells neither provided a protective response to T. gondii infection nor mediated autoimmune colitis [74]. The expression of the BMI-1-and EZH2-containing PcG complexes in mature T cells is mutually exclusive, but they both play important roles in various stages of $\mathrm{T}$ cell differentiation [75]. EZH2 is highly expressed in 
developing murine lymphocytes and plays a critical role in early B cell development, rearrangement of the immunoglobulin heavy chain gene and regulation on histone $\mathrm{H} 3$ methylation in early B cell progenitors [54].

Here, we observed that, upon MG infection, gga-miR-101-3p is up-regulated in the lung tissue. One can imagine that the up-regulated gga-miR-101-3p would inhibit EZH2 expression, which, in turn, impairs T-cell function. Therefore, gga-miR-101-3p and EZH2 may be a privilege niche for MG to overcome the host immunity. Both gga-miR-101-3p and EZH2 can be used as potential diagnostic biomarkers and therapeutic targets in treatment and prevention of MG infection.

Since both miR-101 and EZH2 are highly conserved in a wide range of species (Figure 1C), the results obtained in chicken in this study will provide useful information and insights for the studies of other species.

\section{Materials and Methods}

\subsection{Predication of gga-miR-101-3p Target Genes}

The databases miRDB [48] and TargetScan [46] were used to search the target genes of gga-miR-101-3p. The duplex and the minimum free energy (mFE) between gga-miR-101-3p and $3^{\prime}$-UTR of the potential targets were analyzed by RNA hybrid [49].The conservatism of the target gene was analyzed by TargetScan [46]. AmiGo [50] was used to analyze functions of the target genes of gga-miR-101-3p in Gallus gallus.

\subsection{Design of DNA Primers and Synthesis of RNA Oligonucleotides}

All sequences of the primers used in this study are shown in Table 1. All RNA oligonucleotides was designed and synthesized by GenePharm (Shanghai, China).The gga-miR-101-3p mimics sequences was $5^{\prime}$-GUACAGUACUGUGAUAACUGAA- $3^{\prime}$. A non-specific miRNA was used as a negative control for gga-miR-101-3p: sense $5^{\prime}$-UUCUCCGAACGUGUCACGUTT- $3^{\prime}$ and antisense $5^{\prime}$-ACGUGACACGUUCGGAGAATT- $3^{\prime}$. An miRNA inhibitor sequences were as follows: gga-miR-101-3p inhibitor, 5'-UUCAGUUAUCACAGUACUGUAC-3'; random miRNA inhibitor negative control, 5'-CAGUACUUUUGUGUAGUACAA-3'.

Table 1. Sequences of DNA primers.

\begin{tabular}{|c|c|c|}
\hline Name & Primer Sequence $\left(5^{\prime}-3^{\prime}\right)$ & Accession No. \\
\hline \multicolumn{3}{|c|}{ Primers for $3^{\prime}$-UTR Cloning } \\
\hline EZH2 $3^{\prime}$-UTR-F & GCGCTCGAGCTGCCTTATCTTC & XM 004935061 \\
\hline EZH2 3'-UTR-R & ATAGCGGCCGCTAGCTGGTGAGA & XM 004935061 \\
\hline \multicolumn{3}{|c|}{ Primers for RT-qPCR } \\
\hline GAPDH-F & GAGGGTAGTGAAGGCTGCTG & NM 204305 \\
\hline GAPDH-R & CACAACACGGTTGCTGTATC & NM 204305 \\
\hline EZH2-F & TGCCTATAATGTACTCATGGTCAC & XM 004935061 \\
\hline EZH2-R & TCATCATTGATAAATCCACАСТСТ & XM 004935061 \\
\hline RT-gga-miR-101-3p & CTCAACTGGTGTCGTGGAGTCGGCAATTCAGTTGAGTTCAGTTA & MIMAT0001185 \\
\hline gga-miR-101-3p-F & CTGGTAGGGTACAGTACTGTGATA & MIMAT0001185 \\
\hline gga-miR-101-3p-R & CTGGTGTCGTGGAGTCGGC & MIMAT0001185 \\
\hline gga-5s-rRNA-F & CCATACCACCCTGGAAACGC & \\
\hline gga-5s-rRNA-R & TACTAACCGAGCCCGACCCT & \\
\hline
\end{tabular}

\subsection{Cell Culture}

DF-1, obtained from American Type Culture Collection, is an immortalized chicken embryonic fibroblast cell line. DF-1 was cultured in Dulbecco's modified eagle medium (DMEM) (Invitrogen, Carlsbad, CA, USA) supplemented with 10\% fetal bovine serum (FBS) (Invitrogen, Carlsbad, CA, USA), $100 \mathrm{U} / \mathrm{mL}$ penicillin $\mathrm{G}$ and $100 \mu \mathrm{g} / \mathrm{mL}$ streptomycin. Cells cultured in a humidified incubator were grown and maintained at $39^{\circ} \mathrm{C}$ with $5 \% \mathrm{CO}_{2}$. 


\subsection{Plasmid Construction}

To construct the dual luciferase reporter plasmid, the full length or the fragments of EZH2 $3^{\prime}$-UTR covering the putative gga-miR-101-3P binding site were amplified by RT-PCR from the cDNA extracted from the lung tissues of chicken. The amplified products were sub-cloned into Xho I and Not I sites of psi-CHECK ${ }^{\mathrm{TM}}$-2 vector (Promega, Madison, WI, USA). The primers were listed in Table 1. All constructs were verified by DNA sequencing. In addition, all transfection experiments were performed in triplicate.

\subsection{Dual-Luciferase Reporter Assay}

Dual luciferase reporter assay was comprised of two reporters. One is Renilla luciferase and the other is a firefly luciferase in pmirGLO containing the assayed $3^{\prime}$-UTR sequence. For luciferase reporter assay, DF-1 cells were plated 1 day before transfection. On the 2nd day, 200 ng of luciferase reporter plasmid and $10 \mathrm{pmol}$ of the indicated RNA oligonucleotides were also transfected into DF-1 using Lipofectamine 2000 (Invitrogen Life Technologies, Carlsbad, CA, USA). The cells were collected at $48 \mathrm{~h}$ of post-transfection, and the dual-luciferase activity assay was performed according to the manufacturer's instructions (Promega, Medison, WI, USA). Luciferase activity was detected using a Lumat LB 9507 Ultra-Sensitive Tube Luminometer (Titertek Berthold, Nanjing, China). Firefly luciferase activity of each sample was normalized by Renilla luciferase activity. All transfection experiments were performed in triplicate and repeated at least three times.

\subsection{Reverse Transcription and Quantitative RT-PCR Analysis}

Expression of gga-miR-101-3p and EZH2 was measured using RT-qPCR. The total RNA from the cultured cells and the frozen lung tissue specimens of chicken embryos were isolated using TRIzol Reagent (Invitrogen, Carlsbad, CA, USA) and purified using RNeasy mini columns according to the manufacturer's instructions (Qiagen; Valencia, CA, USA). Then using the Prime Script ${ }^{\mathrm{TM}} \mathrm{RT}_{\text {reagent }}$ kit with gDNA eraser (TaKaRa, Tokyo, Japan), we performed RT-PCR, in which $1 \mu \mathrm{g}$ of total RNA from each samples was reverse transcribed into cDNA. The Real-time PCR was performed in a TransStart Top Green qPCR SuperMix (TRANSGEN, Beijing, China) on CFX96 or CFX384 Touch ${ }^{\mathrm{TM}}$ (Bio-Rad, Hercules, CA, USA). The relative mRNA levels were calculated using $2^{-\Delta \Delta C t}$ method [76]. The data were analyzed using 7500 software v.2.0.1 (Applied Biosystems, Foster, CA, USA) with the automatic $C_{t}$ setting for adapting baseline and threshold for $C_{t}$ determination. 5S-RNA and glyceraldehyde-3-phosphate dehydrogenase (GAPDH) were used as internal controls, respectively. The experiment was repeated three times. The primers were listed in Table 1.

\subsection{Western Blot Analysis}

The DF-1 cells were cultivated in 6-well plates, 10 pmol of the indicated RNA oligonucleotides were transfected into DF-1 using Lipofectamine 2000 (Invitrogen Life Technologies, Carlsbad, CA, USA). The total proteins were isolated at $60 \mathrm{~h}$ post-transfection using RIPA-buffer (Beyotime, Beijing, China) supplemented with $100 \mathrm{mM}$ phenylmethanesulfonyl fluoride (PMSF). The total protein extracts were measured by the BCA protein assay reagent kit (Beyotime, Beijing, China), $10 \mu \mathrm{g}$ of protein were fractionated on 12\% SDS-polyacrylamide gel electrophoresis (SDA-PAGE) and transferred by electrophoresis to polyvinylidene fluoride (PVDF) membranes (Beyotime, Beijing, China). Membranes were blocked in 5\% $(w / v)$ fat free milk for $1 \mathrm{~h}$ at room temperature. The membrane was incubated overnight with the appropriate primary antibodies, including goat polyclonal anti-EZH2 (Santa Cruz Biotechnology, Inc., Santa Cruz, CA USA) and $\beta$-actin, which served as a protein loading control. Then, the membrane was washed and incubated with rabbit anti-goat secondary antibody for $1 \mathrm{~h}$. Protein on the membrane was detected using an ECL ${ }^{\mathrm{TM}}$ detection system (Bio-Rad, Hercules, CA, USA) after washing in TBST. All experiments were repeated three times. 


\subsection{Cell Proliferation and Cell Cycle Assay}

DF-1 cells were plated at a density of $2 \times 10^{4}$ cells / well in flat-bottom, 96-well cell culture plate and allowed to grow for $4 \mathrm{~h}$ at $39{ }^{\circ} \mathrm{C}$ with $5 \% \mathrm{CO}_{2}$. The DF-1 cells were then transfected with the indicated RNA oligonucleotides. At $24 \mathrm{~h}, 48 \mathrm{~h}, 72 \mathrm{~h}$ of post-transfection, the cells were incubated with $10 \mu \mathrm{L}$ of 3-(4,5-dimethylthiazol-2-yl)-2,5-diphenyltetrazolium bromide (MTT) (5 mg/mL) for $4 \mathrm{~h}$ at $39^{\circ} \mathrm{C} .100 \mu \mathrm{L}$ of Dimethyl Sulphoxide (DMSO) was added to solubilize formanzan. Cell proliferation was measured using a MTT cell proliferation and cytotoxicity assay kit according to the manufacturer's instructions (Beyotime, Beijing, China). The absorbance at $595 \mathrm{~nm}$ of each well was scanned in a microplate reader (Bio-Rad, Hercules, CA, USA).

The cell cycle assay was performed in six 6-well plates. Similarly, DF-1 cells were transfected with the RNA oligonucleotides. At $48 \mathrm{~h}$ of post-transfection, cell cycle was analyzed in a flow cytometry using a cell cycle detection kit (KeyGEN, Nanjing, China). At least eight replicate wells were included for each experimental group, and all experiments were repeated independently three times.

\subsection{Mycoplasma Strains and Growth Condition}

MG-HS was isolated from a chicken farm in Hubei province, China [17,18]. MG-HS was deposited and donated by State Key Laboratory of Agricultural Microbiology, College of Veterinary Medicine, Huazhong Agricultural University (Wuhan, China). MG-HS were cultured at $37{ }^{\circ} \mathrm{C}$ in modified FM-4 medium supplemented with $12 \%(v / v)$ porcine serum and $10 \%$ yeast extract until mid-log phase. The concentration of MG-HS is determined by acid-mediated shift of phenol red dye from red to orange as previously described [17]. The number of viable Mycoplasmas in a suspension was then determined by color changing units assay [77].

\subsection{Infection Experiments}

MG infection experiments were divided into experimental group and control group, and carried out in 6-well plates. Cell monolayers were detached from cell culture vials by trypsin treatment, seeded in 6-well plates evenly, and incubated in the medium without antibiotics. The cells of experimental group at $80 \%-90 \%$ confluency were infected with $100 \mu \mathrm{L}$ of MG at mid exponential phase $\left(1 \times 10^{10} \mathrm{CCU} / \mathrm{mL}\right)$. At the $24 \mathrm{~h}$ of post-infection, the cells in the two groups were collected with Trizol (Invitrogen, Carlsbad, CA, USA) for further use.

Two-hundred embryos of White Leghorn SPF chicken were used for the MG challenge experiment. At the 9th hatching day, 100 chicken embryos were injected with $300 \mu \mathrm{L}$ of MG-HS strains at $10^{10} \mathrm{CCU} / \mathrm{mL}$ into allantoic cavity. The remaining 100 chicken embryos were injected with the same dosage of diluent as controls. The viability of chick-embryos was examined by eyes under a candling machine. The dead chick-embryos were eliminated. Chicken embryo mortality rate of infection group and control group were $12.3 \%$ and $7 \%$, respectively. The whole lung tissue samples from 6 infected live chicken embryos and 6 controls were collected on the 9th-11th days of post-infection, and stored in the RNA fixer (BioTeke Co., Ltd., Beijing, China).

\subsection{Statistical Analysis}

Data are expressed as the mean value \pm SD of at least three independent experiments. Statistically significant differences were assessed using Student's $t$-test. $\quad p$-values $<0.05$ were considered significant. Significant differences were denoted as $*<0.05,{ }^{* *} p<0.01$.

Acknowledgments: This study was funded by the National Natural Science Foundation of China (Grant No. 31070154 and 31270216). The funders played no role in the study design, data collection and analysis, the decision to publish, or in the preparation of the manuscript. 
Author Contributions: Jiao Chen performed the experiments; Zaiwei Wang performed total RNA isolation and cDNA preparation; Dingren Bi guided experiments; Yue Hou and Yabo Zhao helped to analyse and interpret data. Jianjun Sun helped to draft the manuscript. Xiuli Peng conceived and designed the study and helped to draft the manuscript. All authors read and approved the final manuscript.

Conflicts of Interest: The authors declare no conflict of interest.

\section{References}

1. Chazel, M.; Tardy, F.; le Grand, D.; Calavas, D.; Poumarat, F. Mycoplasmoses of ruminants in France: Recent data from the national surveillance network. BMC Vet. Res. 2010, 6, 32. [CrossRef] [PubMed]

2. Atkinson, T.P.; Balish, M.F.; Waites, K.B. Epidemiology, clinical manifestations, pathogenesis and laboratory detection of Mycoplasma pneumoniae infections. FEMS Microbiol. Rev. 2008, 32, 956-973. [CrossRef] [PubMed]

3. Gambarini, M.; Kunz, T.; Oliveira Filho, B.; Porto, R.; Oliveira, C.; Brito, W.; Viu, M. Granular Vulvovagini Syndrome in nelore pubertal and post pubertal replacement heifers under tropical conditions: Role of Mycoplasma spp., Ureaplasma diversum and BHV-1. Trop. Anim. Health Prod. 2009, 41, 1421-1426. [CrossRef] [PubMed]

4. May, M.; Brown, D.R. Secreted sialidase activity of canine Mycoplasmas. Vet. Microbiol. 2009, 137, $380-383$. [CrossRef] [PubMed]

5. McVey, J.P. An overview of the US/Japan natural resource's panel on aquaculture: Past, present and future. Bull. Fish. Res. Agency 2010, 29, 1-8.

6. Osman, K.; Aly, M.; Amin, Z.; Hasan, B. Mycoplasma gallisepticum: An emerging challenge to the poultry industry in Egypt. Rev. Sci. Technol. 2009, 28, 1015-1023.

7. Sykes, J.E. Feline hemotropic Mycoplasmas. J. Vet. Emerg. Crit. Care 2010, 20, 62-69. [CrossRef] [PubMed]

8. Ley, D.H. Mycoplasma gallisepticum infection. In Diseases of Poultry, 11th ed.; Iowa State Univerity Press: Ames, IA, USA, 2003; pp. 722-743.

9. Yoder, H.W., Jr. Mycoplasma gallisepticum infection. Dis. Poult. 1991, 9, 198-212.

10. Davidson, W.; Nettles, V.; Couvillion, C.; Yoder, H., Jr. Infectious sinusitis in wild turkeys. Avian Dis. 1982, 26, 402-405. [CrossRef] [PubMed]

11. Amin, M.; Jordan, F. Infection of the chicken with a virulent or avirulent strain of Mycoplasma gallisepticum alone and together with Newcastle disease virus or E. coli or both. Vet. Microbiol. 1979, 4, 35-45. [CrossRef]

12. Stipkovits, L.; Egyed, L.; Palfi, V.; Beres, A.; Pitlik, E.; Somogyi, M.; Szathmary, S.; Denes, B. Effect of low-pathogenicity influenza virus H3N8 infection on Mycoplasma gallisepticum infection of chickens. Avian Pathol. 2012, 41, 51-57. [CrossRef]

13. Fürnkranz, U.; Siebert-Gulle, K.; Rosengarten, R.; Szostak, M.P. Factors influencing the cell adhesion and invasion capacity of Mycoplasma gallisepticum. Acta Vet. Scand. 2013, 55, 63. [CrossRef] [PubMed]

14. Indiková, I.; Much, P.; Stipkovits, L.; Siebert-Gulle, K.; Szostak, M.P.; Rosengarten, R.; Citti, C. Role of the GapA and CrmA cytadhesins of Mycoplasma gallisepticum in promoting virulence and host colonization. Infect. Immunity 2013, 81, 1618-1624. [CrossRef] [PubMed]

15. Jenkins, C.; Geary, S.J.; Gladd, M.; Djordjevic, S.P. The Mycoplasma gallisepticum OsmC-like protein MG1142 resides on the cell surface and binds heparin. Microbiology 2007, 153, 1455-1463. [CrossRef] [PubMed]

16. Winner, F.; Rosengarten, R.; Citti, C. In vitro cell invasion of Mycoplasma gallisepticum. Infect. Immun. 2000, 68, 4238-4244. [CrossRef] [PubMed]

17. Bi, D.; Ji, X. The isolation and identification of the Mycoplasma gallisepticum. Acta Vet. Zootechnol. Sin. 1988, $1,146-148$.

18. Bi, D.; Xu, Q. Study on pathogenicity of HS strain Mycoplasma gallisepticum. Chin. J. Anim. Poult. Infect. Dis. 1997, 5, 24-26.

19. Marois, C.; Dufour-Gesbert, F.; Kempf, I. Polymerase chain reaction for detection of Mycoplasma gallisepticum in environmental samples. Avian Pathol. 2002, 31, 163-168. [CrossRef] [PubMed]

20. Pennycott, T.; Dare, C.; Yavari, C.; Bradbury, J. Mycoplasma sturni and Mycoplasma gallisepticum in wild birds in Scotland. Vet. Rec. 2005, 156, 513-515. [CrossRef] [PubMed]

21. Lee, R.C.; Feinbaum, R.L.; Ambros, V. The C. elegans heterochronic gene lin-4 encodes small RNAs with antisense complementarity to lin-14. Cell 1993, 75, 843-854. [CrossRef] 
22. miRBase: The microRNA Database. Available online: http://www.mirbase.org/cgi-bin/query.pl?terms=gga (accessed on 27 January 2015).

23. Ambros, V. The functions of animal microRNAs. Nature 2004, 431, 350-355. [CrossRef] [PubMed]

24. Shyu, A.B.; Wilkinson, M.F.; van Hoof, A. Messenger RNA regulation: To translate or to degrade. EMBO J. 2008, 27, 471-481. [CrossRef] [PubMed]

25. Liu, J. Control of protein synthesis and mRNA degradation by microRNAs. Curr. Opin. Cell Biol. 2008, 20, 214-221. [CrossRef] [PubMed]

26. Filipowicz, W.; Bhattacharyya, S.N.; Sonenberg, N. Mechanisms of post-transcriptional regulation by microRNAs: Are the answers in sight? Nat. Rev. Genet. 2008, 9, 102-114. [CrossRef] [PubMed]

27. Bartel, D.P. MicroRNAs: Genomics, biogenesis, mechanism, and function. Cell 2004, 116, $281-297$. [CrossRef]

28. Rigoutsos, I. New tricks for animal microRNAS: Targeting of amino acid coding regions at conserved and nonconserved sites. Cancer Res. 2009, 69, 3245-3248. [CrossRef] [PubMed]

29. Di Leva, G.; Calin, G.A.; Croce, C.M. MicroRNAs: Fundamental facts and involvement in human diseases. Birth Defects Res. C Embryo Today 2006, 78, 180-189. [CrossRef] [PubMed]

30. Lim, L.P.; Glasner, M.E.; Yekta, S.; Burge, C.B.; Bartel, D.P. Vertebrate microRNA genes. Science 2003, 299, 1540. [CrossRef] [PubMed]

31. Li, H.; Shang, H.; Shu, D.; Zhang, H.; Ji, J.; Sun, B.; Li, H.; Xie, Q. gga-miR-375 plays a key role in tumorigenesis post subgroup J avian leukosis virus infection. PLoS ONE 2014, 9, e90878. [CrossRef] [PubMed]

32. Wang, Q.; Gao, Y.; Ji, X.; Qi, X.; Qin, L.; Gao, H.; Wang, Y.; Wang, X. Differential expression of microRNAs in avian leukosis virus subgroup J-induced tumors. Vet. Microbiol. 2013, 162, 232-238. [CrossRef] [PubMed]

33. Wang, Y.; Brahmakshatriya, V.; Zhu, H.; Lupiani, B.; Reddy, S.M.; Yoon, B.J.; Gunaratne, P.H.; Kim, J.H.; Chen, R.; Wang, J. Identification of differentially expressed miRNAs in chicken lung and trachea with avian influenza virus infection by a deep sequencing approach. BMC Genom. 2009, 10, 512. [CrossRef] [PubMed]

34. Wang, Y.S.; Ouyang, W.; Pan, Q.X.; Wang, X.L.; Xia, X.X.; Bi, Z.W.; Wang, Y.Q.; Wang, X.M. Overexpression of microRNA gga-miR-21 in chicken fibroblasts suppresses replication of infectious bursal disease virus through inhibiting VP1 translation. Antivir. Res. 2013, 100, 196-201. [CrossRef] [PubMed]

35. Yao, Y.; Zhao, Y.; Xu, H.; Smith, L.P.; Lawrie, C.H.; Watson, M.; Nair, V. MicroRNA profile of Marek's disease virus-transformed T-cell line MSB-1: Predominance of virus-encoded microRNAs. J. Virol. 2008, 82, 4007-4015. [CrossRef] [PubMed]

36. Lian, L.; Qu, L.; Chen, Y.; Lamont, S.J.; Yang, N. A systematic analysis of miRNA transcriptome in Marek's disease virus-induced lymphoma reveals novel and differentially expressed miRNAs. PLoS ONE 2012, 7, e51003. [CrossRef] [PubMed]

37. Stik, G.; Dambrine, G.; Pfeffer, S.; Rasschaert, D. The oncogenic microRNA OncomiR-21 overexpressed during Marek's disease lymphomagenesis is transactivated by the viral oncoprotein Meq. J. Virol. 2013, 87, 80-93. [CrossRef] [PubMed]

38. Li, X.; Lian, L.; Zhang, D.; Qu, L.; Yang, N. gga-miR-26a targets NEK6 and suppresses Marek's disease lymphoma cell proliferation. Poult. Sci. 2014, 93, 1097-1105. [CrossRef] [PubMed]

39. Lee, J.Y.; Jeong, W.; Kim, J.H.; Kim, J.; Bazer, F.W.; Han, J.Y.; Song, G. Distinct expression pattern and post-transcriptional regulation of cell cycle genes in the glandular epithelia of avian ovarian carcinomas. PLOS ONE 2012, 7, e51592. [CrossRef] [PubMed]

40. Zhang, J.G.; Guo, J.F.; Liu, D.L.; Liu, Q.; Wang, J.J. MicroRNA-101 exerts tumor-suppressive functions in non-small cell lung cancer through directly targeting enhancer of zeste homolog 2. J. Thorac. Oncol. 2011, 6, 671-678. [CrossRef] [PubMed]

41. Cho, H.M.; Jeon, H.S.; Lee, S.Y.; Jeong, K.J.; Park, S.Y.; Lee, H.Y.; Lee, J.U.; Kwon, S.J.; Choi, E.; Na, M.J. microRNA-101 inhibits lung cancer invasion through the regulation of enhancer of zeste homolog 2. Exp. Ther. Med. 2011, 2, 963-967. [PubMed]

42. Yang, J.; Lu, Y.; Lu, M.; Leng, R.; Pan, H.; Ye, D. MicroRNA-101, mitogen-activated protein kinases and mitogen-activated protein kinases phosphatase-1 in systemic lupus erythematosus. Lupus 2013, 22, 115-120. [CrossRef] [PubMed]

43. Zhu, Q.Y.; Liu, Q.; Chen, J.X.; Lan, K.; Ge, B.X. MicroRNA-101 targets MAPK phosphatase-1 to regulate the activation of MAPKs in macrophages. J. Immunol. 2010, 185, 7435-7442. [CrossRef] [PubMed] 
44. Huang, F.; Lin, C.; Shi, Y.; Kuerban, G. MicroRNA-101 inhibits cell proliferation, invasion, and promotes apoptosis by regulating cyclooxygenase-2 in HeLa cervical carcinoma cells. Asian Pac. J. Cancer Prev. 2013, 14, 5915. [CrossRef] [PubMed]

45. He, L.; Hannon, G.J. MicroRNAs: Small RNAs with a big role in gene regulation. Nat. Rev. Genet. 2004, 5, 522-531. [CrossRef] [PubMed]

46. Target Scan Human. Available online: http://www.targetscan.org/ (accessed on 10 November 2014).

47. miRecords. Available online: http://c1.accurascience.com/miRecords/ (accessed on 10 November 2014).

48. miRDB. Available online: http://www.mirdb.org/miRDB/ (accessed on 10 November 2014).

49. RNAhybrid. Available online: http://bibiserv.techfak.uni-bielefeld.de/rnahybrid/ (accessed on 10 November 2014).

50. AmiGO 2. Available online: http://amigo.geneontology.org (accessed on 10 December 2014).

51. Wu, C.; Chen, Z.; Kuchroo, V.K. EZH2 lines up the chromatin in T regulatory cells. Immunity 2015, 42, 201-203. [CrossRef] [PubMed]

52. DuPage, M.; Chopra, G.; Quiros, J.; Rosenthal, W.L.; Morar, M.M.; Holohan, D.; Zhang, R.; Turka, L.; Marson, A.; Bluestone, J.A. The chromatin-modifying enzyme EZH2 is critical for the maintenance of regulatory $\mathrm{T}$ cell identity after activation. Immunity 2015, 42, 227-238. [CrossRef] [PubMed]

53. Komatsu, N.; Okamoto, K.; Sawa, S.; Nakashima, T.; Oh-hora, M.; Kodama, T.; Tanaka, S.; Bluestone, J.A.; Takayanagi, H. Pathogenic conversion of Foxp3+ T cells into TH17 cells in autoimmune arthritis. Nat. Med. 2014, 20, 62-68. [CrossRef] [PubMed]

54. Su, I.H.; Basavaraj, A.; Krutchinsky, A.N.; Hobert, O.; Ullrich, A.; Chait, B.T.; Tarakhovsky, A. EZH2 controls B cell development through histone H3 methylation and Igh rearrangement. Nat. Immunol. 2003, 4, 124-131. [CrossRef] [PubMed]

55. O'Carroll, D.; Erhardt, S.; Pagani, M.; Barton, S.C.; Surani, M.A.; Jenuwein, T. The Polycomb-group gene EZH2 Is required for early mouse development. Mol. Cell. Biol. 2001, 21, 4330-4336. [CrossRef] [PubMed]

56. http://www.gene.ucl.ac.uk/nomenclature/guidelines.html (accessed on 10 December 2014).

57. Yan, J.; Gumireddy, K.; Li, A.; Huang, Q. Regulation of mesenchymal phenotype by MicroRNAs in cancer. Curr. Cancer Drug Targets 2013, 13, 930. [CrossRef] [PubMed]

58. Zhong, X.; Coukos, G.; Zhang, L. miRNAs in human cancer. Methods Mol. Biol. 2012, 822, $295-306$. [PubMed]

59. Barton, G.M.; Medzhitov, R. Toll-like receptor signaling pathways. Science 2003, 300, 1524-1525. [CrossRef] [PubMed]

60. Beutler, B. Inferences, questions and possibilities in Toll-like receptor signalling. Nature 2004, 430, $257-263$. [CrossRef] [PubMed]

61. Muzio, M.; Polentarutti, N.; Bosisio, D.; Manoj, K.P.; Mantovani, A. Toll-like receptor family and signalling pathway. Biochem. Soc. Trans. 2000, 28, 563-566. [CrossRef] [PubMed]

62. Valente, A.J.; Yoshida, T.; Gardner, J.D.; Somanna, N.; Delafontaine, P.; Chandrasekar, B. Interleukin-17A stimulates cardiac fibroblast proliferation and migration via negative regulation of the dual-specificity phosphatase MKP-1/DUSP-1. Cell Signal. 2012, 24, 560-568. [CrossRef] [PubMed]

63. Tonini, T.; D'Andrilli, G.; Fucito, A.; Gaspa, L.; Bagella, L. Importance of EZH2 polycomb protein in tumorigenesis process interfering with the pathway of growth suppressive key elements. J. Cell. Physiol. 2008, 214, 295-300. [CrossRef] [PubMed]

64. Bachmann, I.M.; Halvorsen, O.J.; Collett, K.; Stefansson, I.M.; Straume, O.; Haukaas, S.A.; Salvesen, H.B.; Otte, A.P.; Akslen, L.A. EZH2 expression is associated with high proliferation rate and aggressive tumor subgroups in cutaneous melanoma and cancers of the endometrium, prostate, and breast. J. Clin. Oncol. 2006, 24, 268-273. [CrossRef] [PubMed]

65. Varambally, S.; Cao, Q.; Mani, R.S.; Shankar, S.; Wang, X.; Ateeq, B.; Laxman, B.; Cao, X.; Jing, X.; Ramnarayanan, K. Genomic loss of microRNA-101 leads to overexpression of histone methyltransferase Ezh2 in cancer. Science 2008, 322, 1695-1699. [CrossRef] [PubMed]

66. Li, K.; Liu, C.; Zhou, B.; Bi, L.; Huang, H.; Lin, T.; Xu, K. Role of EZH2 in the growth of prostate cancer stem cells isolated from LNCaP cells. Int. J. Mol. Sci. 2013, 14, 11981-11993. [CrossRef] [PubMed]

67. Cao, P.; Deng, Z.; Wan, M.; Huang, W.; Cramer, S.D.; Xu, J.; Lei, M.; Sui, G. Research MicroRNA-101 negatively regulates EZH2 and its expression is modulated by androgen receptor and HIF- $1 \alpha / \mathrm{HIF}-1 \beta$. Mol. Cancer 2010, 9, 108. [CrossRef] [PubMed] 
68. Wang, Y.; Xiang, W.; Wang, M.; Huang, T.; Xiao, X.; Wang, L.; Tao, D.; Dong, L.; Zeng, F.; Jiang, G. Methyl jasmonate sensitizes human bladder cancer cells to gambogic acid-induced apoptosis through down-regulation of EZH2 expression by miR-101. Br. J. Pharmacol. 2014, 171, 618-635. [CrossRef] [PubMed]

69. Friedman, J.M.; Liang, G.; Liu, C.C.; Wolff, E.M.; Tsai, Y.C.; Ye, W.; Zhou, X.; Jones, P.A. The putative tumor suppressor microRNA-101 modulates the cancer epigenome by repressing the polycomb group protein EZH2. Cancer Res. 2009, 69, 2623-2629. [CrossRef] [PubMed]

70. Wang, H.J.; Ruan, H.J.; He, X.J.; Ma, Y.Y.; Jiang, X.T.; Xia, Y.J.; Ye, Z.Y.; Tao, H.Q. MicroRNA-101 is down-regulated in gastric cancer and involved in cell migration and invasion. Eur. J. Cancer 2010, 46, 2295-2303. [CrossRef] [PubMed]

71. Lei, Q.; Shen, F.; Wu, J.; Zhang, W.; Wang, J.; Zhang, L. miR-101, downregulated in retinoblastoma, functions as a tumor suppressor in human retinoblastoma cells by targeting EZH2. Oncol. Rep. 2014, 32, 261-269. [CrossRef] [PubMed]

72. Liu, L.; Guo, J.; Yu, L.; Cai, J.; Gui, T.; Tang, H.; Song, L.; Wang, J.; Han, F.; Yang, C. miR-101 regulates expression of EZH2 and contributes to progression of and cisplatin resistance in epithelial ovarian cancer. Tumor Biol. 2014, 35, 12619-12626. [CrossRef] [PubMed]

73. Sachdeva, M.; Wu, H.; Ru, P.; Hwang, L.; Trieu, V.; Mo, Y. MicroRNA-101-mediated Akt activation and estrogen-independent growth. Oncogene 2011, 30, 822-831. [CrossRef] [PubMed]

74. Yang, X.P.; Jiang, K.; Hirahara, K.; Vahedi, G.; Afzali, B.; Sciume, G.; Bonelli, M.; Sun, H.W.; Jankovic, D.; Kanno, Y. EZH2 is crucial for both differentiation of regulatory T cells and T effector cell expansion. Sci. Rep. 2015, 5, 10643. [CrossRef] [PubMed]

75. Raaphorst, F.M.; Otte, A.P.; van Kemenade, F.J.; Blokzijl, T.; Fieret, E.; Hamer, K.M.; Satijn, D.P.; Meijer, C.J. Distinct BMI-1 and EZH2 expression patterns in thymocytes and mature T cells suggest a role for Polycomb genes in human T cell differentiation. J. Immunol. 2001, 166, 5925-5934. [CrossRef] [PubMed]

76. Livak, K.J.; Schmittgen, T.D. Analysis of relative gene expression data using real-time quantitative PCR and the $2^{-\Delta \Delta C t}$ method. Methods 2001, 25, 402-408. [CrossRef] [PubMed]

77. Calus, D.; Maes, D.; Vranckx, K.; Villareal, I.; Pasmans, F.; Haesebrouck, F. Validation of ATP luminometry for rapid and accurate titration of Mycoplasma hyopneumoniae in Friis medium and a comparison with the color changing units assay. J. Microbiol. Methods 2010, 83, 335-340. [CrossRef] [PubMed]

(C) 2015 by the authors; licensee MDPI, Basel, Switzerland. This article is an open access article distributed under the terms and conditions of the Creative Commons by Attribution (CC-BY) license (http://creativecommons.org/licenses/by/4.0/). 